\section{6 OPEN ACCESS}

\title{
Oral health and impact on performance of athletes participating in the London 2012 Olympic Games: a cross-sectional study
}

\author{
I Needleman, ${ }^{1}$ P Ashley, ${ }^{2}$ A Petrie, ${ }^{3}$ F Fortune, ${ }^{4}$ W Turner, $_{1}{ }^{4}$ J Jones, ${ }^{4}$ J Niggli, ${ }^{4}$

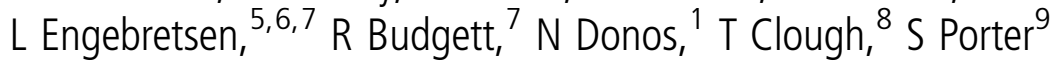

- Online supplementary table S1 to $\mathrm{S} 12$ are published online only. To view please visit the journal online (http://dx.doi. org/10.1136/bjsports-2013092891).

${ }^{1}$ Unit of Periodontology and International Centre for Evidence-Based Oral Health, UCL Eastman Dental Institute, London, UK

${ }^{2}$ Unit of Paediatric Dentistry, UCL Eastman Dental Institute, London, UK

${ }^{3}$ Unit of Biostatistics, UCL Eastman Dental Institute, London, UK

${ }^{4}$ QMUL, London, UK

${ }^{5}$ Department of Sports Medicine, Oslo Sports Trauma Research Center, Norwegian School of Sports Science, Oslo, Norway

${ }^{6}$ Orthopaedic Center, Ullevål University Hospital, University of Oslo, Oslo, Norway ${ }^{7}$ International Olympic Committee Medical

Commission, Lausanne, Switzerland

${ }^{8}$ Dental Practice, Chelmsford, UK

${ }^{9}$ Unit of Oral Medicine, UCL Eastman Dental Institute, London, UK

\section{Correspondence to} Professor I Needleman, Unit of Periodontology and International Centre for Evidence-Based Oral Health, UCL Eastman Dental Institute, 256 Gray's Inn Road, London WC1X 8LD, UK;

i.needleman@ucl.ac.uk

Accepted 3 September 2013

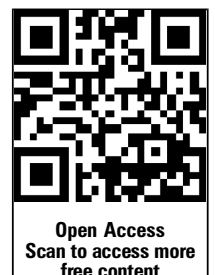

To cite: Needleman I, Ashley P, Petrie A, et al. Br J Sports Med 2013;47:10541058.

\section{ABSTRACT}

Background Oral health is important both for wellbeing and successful elite sporting performance. Reports from Olympic Games have found significant treatment needs; however, few studies have examined oral health directly. The aim of this study was to evaluate oral health, the determinants of oral health and the effect of oral health on well-being, training and performance of athletes participating in the London 2012 Games.

Methods Cross-sectional study at the dental clinic within the Polyclinic in the athletes' village. Following informed consent, a standardised history, clinical examination and brief questionnaire were conducted. Results 302 athletes from 25 sports were recruited with data available for 278 . The majority of athletes were from Africa, the Americas and Europe. Overall, the results demonstrated high levels of poor oral health including dental caries (55\% athletes), dental erosion (45\% athletes) and periodontal disease (gingivitis $76 \%$ athletes, periodontitis 15\% athletes). More than $40 \%$ of athletes were 'bothered' by their oral health with $28 \%$ reporting an impact on quality of life and $18 \%$ on training and performance. Nearly half of the participants had not undergone a dental examination or hygiene care in the previous year.

Conclusions The oral health of athletes attending the dental clinic of the London 2012 Games was poor with a resulting substantial negative impact on well-being, training and performance. As oral health is an important element of overall health and well-being, health promotion and disease prevention interventions are urgently required to optimise athletic performance.

\section{BACKGROUND}

Reports from previous summer and winter Olympic Games indicate that there is a significant oral health treatment need for athletes and suggest that there may be high levels of oral health problems. ${ }^{1-6}$ Data on the oral health of elite athletes are important for a number of reasons. First, it is important to understand the oral health of athletes in order to determine whether there is a need to implement relevant preventive care programmes. ${ }^{7}$ Second, oral health data are important for planning of dental services at Olympic Games. Such information is essential to determining the size of resources required to meet the anticipated need and skill mix of the dental team. A further reason for data acquisition is that poor oral health negatively affects oral health-related quality of life. ${ }^{8}$ It is possible that such an impact could adversely affect athletic performance and training. However, there are few data available that have explored this relationship.

A recent International Olympic Committee (IOC) Medical Commission report called 'for further studies to assess more accurately the oral health of the athlete population'. ${ }^{7}$ Most of the published studies to date have not investigated oral health directly, but, instead, have reported on the dental care provided during the games as a proxy for oral health status. Therefore, in view of the increasing demand for oral care at Olympic Games and the recognised priority for further research, the aim of this study was to evaluate the oral health of elite athletes participating in the London 2012 games and the impact of oral health on well-being, training and performance.

\section{METHODS}

Study design

This was a cross-sectional survey.

\section{Eligibility criteria and setting}

All athletes participating in the London 2012 Games and able to understand the consent process (or attending with a translator) were eligible. Recruitment took place in the dental clinic of the polyclinic. Athletes attended the dental clinic for a variety of reasons including periodic dental examination and hygiene care, dental problems and provision of mouthguards. Recruitment started 10 days prior to the opening ceremony and finished 1 day following the closing ceremony.

\section{Data collection}

Data collection was designed to minimise as far as possible its impact on both athletes and clinic staff. Following written informed consent, a systematic oral health assessment and history was conducted in the dental clinic by experienced dentists. Data collection was anonymised and entered directly into the dental clinic software (R4, Carestream Kodak, Stevenage, UK).

Domains of information included athlete demographics, health behaviours, oral health status and self-reported impacts of oral health. The clinical data recorded included presence of dental caries (enamel or dentine) and number of teeth with restorations. Dental erosion was measured using a modification of the Basic Erosive Wear Examination ${ }^{9}$ where 1=loss of enamel surface texture, $2=$ distinct defect but less than $50 \%$ of individual tooth surface area, $3=$ more than $50 \%$ surface area and $9=$ unscorable if tooth surface covered by restoration. A score of 2 and 3 
usually included underlying dentine. In our modification, only the worst individual score for the anterior region and the posterior region were recorded. Previous or presenting history of orofacial trauma and whether sport related was also recorded.

Periodontal health was measured using the Basic Periodontal Examination. ${ }^{10}$ The mouth was divided into six sextants and third molars were excluded from the assessment. A WHO Community Index of Periodontal Treatment Need (CPITN) probe was used to explore the periodontal tissues with a light probing force. The worst finding for each sextant was recorded: Code $0=$ health, code 1 =gum bleeding after gentle probing,

Table 1 Characteristics of athletes

\begin{tabular}{|c|c|c|}
\hline & $\mathbf{N}$ & Percentage \\
\hline Gender & $\mathrm{N}=278$ & \\
\hline Male & 159 & 57.2 \\
\hline Female & 119 & 42.8 \\
\hline Continent & $N=278$ & \\
\hline Africa & 78 & 28.1 \\
\hline America & 81 & 29.1 \\
\hline Europe & 59 & 21.2 \\
\hline Asia & 27 & 9.7 \\
\hline Oceania & 33 & 11.9 \\
\hline Ethnicity & $N=250$ & \\
\hline White & 85 & 34.0 \\
\hline Asian & 7 & 2.8 \\
\hline Black & 79 & 31.6 \\
\hline Dual & 41 & 16.4 \\
\hline Other & 38 & 15.2 \\
\hline Sport (top 10) & $N=272$ & \\
\hline Track and field & 95 & 34.9 \\
\hline Boxing & 38 & 14.0 \\
\hline Hockey & 31 & 11.4 \\
\hline Swimming & 21 & 7.7 \\
\hline Waterpolo & 11 & 4.0 \\
\hline Judo & 10 & 3.7 \\
\hline Volleyball & 8 & 2.9 \\
\hline Shooting & 7 & 2.6 \\
\hline Football & 6 & 2.2 \\
\hline Weightlifting & 6 & 2.2 \\
\hline $\begin{array}{l}\text { Fencing, archery, handball, beach volleyball, taekwondo, } \\
\text { wrestling, cycling, basketball, canoeing, gymnastics, } \\
\text { equestrian, sailing, table tennis, rowing, badminton }\end{array}$ & 39 & 14.3 \\
\hline Last visit of dental check-up or dental hygiene & $\mathrm{N}=275$ & \\
\hline Never & 24 & 8.7 \\
\hline Less than 12 months ago & 123 & 44.7 \\
\hline More than 12 months ago & 128 & 46.5 \\
\hline Mouthguard use in sport & $\mathrm{N}=269$ & \\
\hline No & 186 & 69.4 \\
\hline Yes & 82 & 30.6 \\
\hline If using mouthguard in sport & $\mathrm{N}=83$ & \\
\hline Boil and bite & 35 & 42.2 \\
\hline Custom made & 48 & 57.8 \\
\hline Tobacco use & $\mathrm{N}=272$ & \\
\hline Current & 13 & 4.8 \\
\hline Former & 20 & 7.4 \\
\hline Never & 86 & 87.9 \\
\hline If using tobacco & $\mathrm{N}=25$ & \\
\hline Smoking & 19 & 76 \\
\hline Chewing tobacco & 5 & 20 \\
\hline Smokeless & 1 & 4.0 \\
\hline
\end{tabular}

code $2=$ calculus or restoration overhangs, code $3=$ periodontal pockets of 3.5-5.5 $\mathrm{mm}$ and code $4=$ pockets of $6 \mathrm{~mm}$ or deeper. Mucosal health was assessed as healthy or unhealthy (white/red patches or ulceration) and pericoronitis was assessed as presence or absence of clinical features and with or without symptoms.

Impact of oral health on athletic performance and training was assessed using a modification of the shortened global evaluation of impact of oral health on quality of life ${ }^{11}$ by asking the following questions.

A. To what extent have you been 'bothered' by your mouth, teeth or gums in the last 12 months?

B. To what extent have your mouth, teeth or gums affected your quality of life overall in the last 12 months?

C. To what extent have your mouth, teeth or gums affected your athletic performance or training over the last 12 months?

The responses to the questions were scored on a 5-point scale; not at all, a little, somewhat, a fair amount and a great deal.

\section{Examiner training}

Prior to the study, a $1 \mathrm{~h}$ training session for all members of the dental team was provided in the dental clinic to cover the purpose of the study, research protocol and data collection. Written materials were made available to all dental clinic personnel. Electronic data collection quality was monitored daily and additional training provided as required throughout the study.

\section{Data management and analysis}

Anonymised data were exported and checked and imported into SPSS (IBM Corp. Released 2012. IBM SPSS Statistics for Windows, V.21.0, IBM Corp., Armonk, New York, USA). Descriptive statistics were provided using mean or median and range depending on the distribution of the data. The following tests were used to explore the effect determinants of oral health and impact on performance. The $\chi^{2}$ or Fisher's exact test, as appropriate, were used if the data were categorical. If the data were numerical, the non-parametric Mann-Whitney test was used to compare the distributions of two groups and the Kruskal-Wallis test was used to compare the distributions of three or more groups. If significant, the latter was followed by two-group non-parametric tests. A significance level of 0.05 was used throughout.

\section{RESULTS}

A total of 302 athletes were recruited with data available for up to 278. Missing data resulted from participants not being available for data collection following consent, incomplete data collection or a lack of transfer of data.

\section{Characteristics of athletes}

The mean age of athletes was 25.7 years (range 16-47 years) and $57 \%$ were men (table 1). The majority of athletes were from Africa, America and Europe and were either white or black. Participants represented 25 sports with track and field, boxing and hockey being the most common. Nearly half $(46.5 \%)$ of the athletes reported not attending a check-up or hygiene visit within 12 months of the Games and 8.7\% reported never receiving such care. Of those using mouthguards for sport, more than $40 \%$ used a boil and bite type, that is, not custom-made. Five per cent of athletes reported current tobacco use with $7.4 \%$ as former users. 


\section{Oral health}

Teeth present, caries and restorations

The mean number of teeth per athlete was 29.7 (range 22-32). More than half of athletes presented with dental caries $(55.1 \%)$ of which $41 \%$ was into dentine, that is, irreversible. In terms of extent, an average of two teeth were affected by enamel or dentine caries for each athlete (range 0-14). An average of 3.44 restored teeth per athlete was found (range 0-24) (see online supplementary tables S1 and S2).

\section{Dental erosion}

Dental erosion was present in $44.6 \%$ of athletes with a similar distribution in anterior and posterior regions. In those with erosion, the severity in the most affected tooth was moderate to severe (grade 2-3) in $37.6 \%$ anterior teeth and $48 \%$ posterior teeth (see online supplementary table S3).

\section{Dental and orofacial trauma}

Thirty per cent of athletes reported a history of previous orofacial trauma. The number of athletes in the sample presenting with new trauma was $22(17.6 \%)$ of which $16(32.7 \%)$ were wearing mouthguards. The face and lips were the most common sites affected (see online supplementary table S4).

\section{Periodontal health}

Good periodontal health was rare. Gingivitis (basic periodontal examination (BPE) codes 1-2), as the worst finding, was present in more than three quarters of athletes and there was irreversible periodontitis (BPE codes 3-4) in more than $15 \%$ of athletes. In terms of extent, at least half of the mouth was affected by gingivitis or periodontitis in $76 \%$ and $8.3 \%$ of athletes, respectively (see online supplementary tables S5 and S6).

\section{Pericoronitis and mucosal health}

Signs of infection around wisdom teeth (pericoronitis) were detected in 25 (9.9\%) of athletes. Ten athletes reported symptoms of pain and signs of unhealthy oral mucosa were found in 29 athletes (11.8\%) (see online supplementary table S7).

\section{Impact of oral health on performance}

There was a substantial self-reported negative impact of oral health on well-being and performance. More than $40 \%$ of athletes presenting to the clinic were bothered by their oral health with $28 \%$ reporting an impact on their quality of life and $18 \%$ reporting an impact on training or performance (see online supplementary table S8).

Association of sports drink use, dental erosion and caries

Frequency of sports drink use was associated with dental erosion on anterior $(p=0.036)$ but not posterior teeth $(\mathrm{p}=0.076)$ or both anterior and posterior teeth combined $(p=0.47)$. When dichotomised to yes/no sport drink use, there was no evidence of an effect on erosion or dental caries ( $p=>0.99$ and $p=0.37$, respectively) (see online supplementary table S9).

\section{Effect of continental location and ethnicity}

Continental location was not significantly associated with either caries $(p=0.46)$ or erosion $(p=0.56)$ (see online supplementary tables S10 and 11). There was evidence of an association between ethnicity and dental caries $(p=0.029)$ but not for dental erosion $(p=0.32)$. Differences for ethnicity were found for periodontal health $(p=0.004)$ (see online supplementary table S5).
White athletes had a statistically significant lower (less diseased) median BPE score than either black $(\mathrm{p}=0.006)$ or 'other' athletes $(p=0.001)$. In relation to location, the median periodontal health score (BPE) was highest in athletes from Africa although this did not quite achieve statistical significance $(p=0.05)$.

\section{Exploration of determinants of quality of life and performance}

Dental caries had a highly statistically significant association with self-reported impacts ('bothered' by oral health, impact of oral health on quality of life or training and performance), whether analysed by median number of carious lesions per athlete or number of athletes with caries $(p<0.001)$. This was true for 'bothered' by $(p<0.001)$ and effect on training and performance $(p<0.001)$ and close to statistically significant for quality of life $(p=0.066)$. There was no evidence of an impact of dental erosion or periodontal disease on this composite athlete-reported outcome measure (see online supplementary table S12).

\section{DISCUSSION \\ Key findings}

There were high levels of oral disease in elite athletes attending the dental clinic at the London 2012 Games, including dental caries (55\% of athletes), dental erosion (45\% athletes) and periodontal disease (gingivitis: 76\% athletes; periodontitis: 15\% athletes). In addition, a clear negative impact of oral health on wellness, quality of life, or training and performance was reported by a large number of athletes.

\section{Comparisons with previous studies}

Direct comparisons with previous Olympic Games data are difficult as they have mostly reported dental service utilisation rather than oral health. Furthermore, the reported data often aggregate information from both athletes and other accredited individuals; the latter accounting for around half of the treatment provided. ${ }^{3}$ However, these studies consistently show that poor oral health is common and demonstrate a substantial amount of dental care is provided to athletes. ${ }^{1-6}$ Furthermore, the trend over successive games has been increasing utilisation of dental services. ${ }^{1}$ At the London 2012 Summer Olympic Games, dental consultations comprised $30 \%$ of all medical visits and were second only to musculoskeletal reasons for attendance. ${ }^{12}$

One of the earliest reports of Olympics data was a pilot study conducted on British athletes prior to the 1968 Games in Mexico City as well as a survey of other athletes participating in the Games themselves. ${ }^{5}$ At a time when fluoride toothpaste use was uncommon, they found a mean of 3.5 carious teeth for British athletes and ranged for other regions from 1.16 (Africa) to 4.5 (North America). Later data of elite athletes outside of the Olympic Games also report poor oral health, in elite triathletes ${ }^{13}$ cyclists $^{14}$ and professional football players. ${ }^{15} 16$ The most common findings from these surveys are of pain from dental origin, caries, dental erosion, fractured teeth and restorations, pericoronitis and periodontal disease, that is, similar findings to the present study.

Previous studies have also reported adverse impacts of oral health on the well-being and performance of athletes including anecdotal evidence from the Olympic Games in Mexico City. More robust data from the 1992 Barcelona Games found a negative effect on everyday life in $41 \%$ of athletes which was similar to the present findings with 5\% reporting an effect on sporting performance. ${ }^{6}$ We found a much higher impact on training and performance $(18 \%)$ which might reflect different methodologies or changes in perception of effect of oral health. However, the method we used for assessing these impacts was a 
simple tool of three questions that might lack sensitivity to identify effects, that is, the true prevalence and severity are higher. Typically, such questionnaires are much longer ${ }^{17}$ but the limited time available to examine and interview athletes prevented the use of these questionnaires in this study.

The association that we found between caries and well-being and performance might be explained by the experience of pain and interference with eating, drinking and sleep due to the caries. Previous studies of younger populations have found similar impacts of caries on life quality. ${ }^{18} 19$ Caries risk and disease levels have repeatedly been found to be high in athletes. ${ }^{4-6}$ This finding might result from frequent carbohydrate intake and reduced salivary flow in athletes. ${ }^{13} 20$ Fluoride toothpaste use, which reduces caries risk, was common among athletes in our sample (data not shown) but was not associated with reduced caries experience.

Other oral health conditions that have been associated with negative impacts on quality of life in general populations include periodontal disease ${ }^{21}$ and pericoronitis ${ }^{22}$ (infection around partially erupted wisdom teeth). Both have also been suggested to affect athletic performance. ${ }^{23}$ Our study did not find an effect on well-being or performance which might reflect the measures used to assess the clinical conditions or the selfreported impacts.

\section{Strengths and limitations of data}

The strengths of this study included the number of athletes recruited $(n=302)$, the comprehensiveness of the oral health assessment and the inclusion of self-reported impacts. The limitations included the selected nature of the sample. The athletes were a sample of those attending the London 2012 Polyclinic and might not represent the oral health of all athletes. However, it is important to recognise that reasons for attendance included not only pain and oral health problems but also both the free mouthguard programme and dental examination. Therefore, attendance of athletes was not always a reflection of oral symptoms or injury. To achieve a full understanding of oral health conditions, an epidemiological study of a representative sample of athletes is needed.

\section{Implications for health and performance}

The poor level of oral health of athletes is not a new finding. ${ }^{5}$ Possible causes include diet, ${ }^{13}$ use of sports drinks, ${ }^{24-26}$ decreased salivary flow during exercise, ${ }^{20}$ exercise-induced immune suppression, ${ }^{27}$ level of knowledge and beliefs related to oral health, difficulty of accessing oral health preventive care due to availability of local services and prioritisation of time. It is however notable that the most prevalent problems found in this study are preventable, that is, dental caries, erosion and periodontal diseases. The effect of poor oral health on these athletes in later life is unknown, but if disease was not managed, it could cause considerable impacts including a high treatment need, tooth loss, reduced oral function and psychological effects. Prevention of oral disease and promotion of oral health should therefore become an essential element of the care of elite athletes. Such programmes are relatively simple to establish. While targeting 'high risk' individuals is potentially a means to focus limited resources, predicting who is a high risk is not straightforward. ${ }^{28}$

The impact of oral health on quality of life, training and performance that we found is notable in view of these individuals' participation in sport at the highest level. Years of sporting preparation could potentially be compromised by common and preventable conditions. Several athletes described to us long periods of inability to train or perform at their desired level due to oral problems. Similar concerns were raised in the first study of oral health of Olympic athletes nearly half a century ago and reiterated more recently: 'The possibility of an athlete losing four hard years of training due to an avoidable dental illness or injury is unacceptable and steps must be taken to prevent these occurrences'. ${ }^{1}$

The 2009 IOC Consensus Statement on Periodic Health Evaluation of Elite Athletes ${ }^{7}$ provided a proposal for the evaluation of oral health and prevention of problems. The data from the present study strengthen these recommendations and provide a basis for broadening the remit across oral health still further. Where available, oral health programmes for athletes should utilise existing local resources with a focus on oral health promotion. In addition, there is a need for regular assessment of oral health leading to individualised prevention depending on risk and early treatment of problems. This could be facilitated by integration of oral health within sports medicine.

Future research should include detailed epidemiological studies of oral health and impact on training and performance capturing a representative sample of athletes. The data could shape the development of oral health strategies for athletes. Differences in oral health might be expected both between sports and between countries necessitating an international approach to such research. The oral health improvement strategies will need to be developed and tested and these could include programmes aimed at changing health behaviour (including knowledge, awareness and oral health promoting activities), diet and the use and formulation of sports drinks and supplements.

\section{Conclusions}

High levels of poor oral health including caries, erosion and periodontal diseases were found in athletes attending the dental clinic of the London 2012 Games. Furthermore, poor oral health produced a substantial negative impact on well-being, training and performance. As oral health is an important element of overall health and well-being for optimal performance, the present results highlight the urgent need for oral health promotion strategies and disease prevention interventions for elite athletes.

\section{What are the new findings?}

- The oral health of athletes attending the dental clinic at the London 2012 Games was poor with high levels of dental caries, dental erosion and periodontal diseases.

- Almost half of the athletes had not received dental assessment or care within 12 months of the Games.

- Oral health had a substantial negative impact on athletes' well-being, training and performance.

How might it impact on clinical practice in the near future?

- Oral health assessment should be part of every athlete's routine medical care.

- Poor oral health can affect well-being, training and performance of athletes.

- Oral health promotion and disease prevention strategies need to be developed to facilitate the health, well-being and performance of elite athletes. 
Acknowledgements The authors would like to express their thanks to the London Organising Committee of the Olympic Games (LOCOG) for their help and support with the study and in particular, Mrs Debbie Jevans, Dr Pam Venning, Mr Andrew Rees and Dr Laurence Gant. This study could not have happened without the tremendous enthusiasm and industry of the many dental clinic staff in reception and dental nursing and in particular the dentists who carried out the data collection: Nicholas Barker, Afolabi Bewaji, Richard Browne, Sally-Anne Button, David Connarty, Len D'Cruz, Elizabeth Fox, Anthony Kilcoyne, Tashfeen Kholasi, Anna Krajewski, Jasdeep Ladhar, Catherine Lawson, Johnny Lea, Louise Mc Allister, Lyndon Meehan, Hitesh Mody, Joelle Mort, Mansoor Qureshi, Jit Panesar, Sunil Savani, Kiaran Weil \& Roy Woodhoo. The authors are also most grateful to Dr Poly Fung and Dr Natalie Leow from the UCL Dental Institute for their invaluable help.

Contributors IN and PA conceived the study. Data analysis was conducted by AP. IN, FF, WT, JJ and JN contributed to study conduct. LE and RB contributed to sports medicine expertise. IN, PA, SP and ND contributed to oral health expertise. AC contributed knowledge of dental clinic activity. IN prepared first draft of the manuscript and is the guarantor.

Funding This work was undertaken at UCL/UCLH who received a proportion of funding from the Department of Health's NIHR Biomedical Research Centres funding scheme.

Competing interests None.

Ethics approval Yorkshire \& Humber-Leeds West Committee (12/YH/0187).

Provenance and peer review Not commissioned; externally peer reviewed.

Open Access This is an Open Access article distributed in accordance with the Creative Commons Attribution Non Commercial (CC BY-NC 3.0) license, which permits others to distribute, remix, adapt, build upon this work non-commercially, and license their derivative works on different terms, provided the original work is properly cited and the use is non-commercial. See: http://creativecommons.org/ licenses/by-nc/3.0/

\section{REFERENCES}

1 Piccininni PM, Fasel R. Sports dentistry and the Olympic Games. I Can Dent Assoc 2005:33:471-83.

2 Fasel R. Analisis de la patologia bucal y la terapeutica realizada en los servicios odontologicos de los Juegos Olimpicos para mejorar la atencion buco-dental de los atletas. PhD thesis, Universidad de Barcelona, 2008.

3 Vougiouklakis G, Tzoutzas J, Farmakis ET, et al. Dental data of the Athens 2004 Olympic and Paralympic Games. Int I Sports Med 2008;29:927-93.

4 Yang XJ, Schamach P, Dai JP, et al. Dental service in 2008 Summer Olympic Games. Br J Sports Med 2011:45:270-4.

5 Forrest JO. Dental condition of Olympic Games contestants—a pilot study, 1968. Dent Pract Dent Rec 1969:20:95-101.

6 Soler BD, Batchelor PA, Sheiham A. The prevalence of oral health problems in participants of the 1992 Olympic Games in Barcelona. Int Dent J 1994;44:44-8.
7 Ljungqvist $A$, Jenoure $P$, Engebretsen $L$, et al. The International Olympic Committee (IOC) Consensus Statement on periodic health evaluation of elite athletes March 2009. Int SportMed J 2009;10:124-44.

8 Locker D. Measuring oral health: a conceptual framework. Comm Dent Health 1988:5:5-13.

9 Bartlett D, Ganss C, Lussi A. Basic Erosive Wear Examination (BEWE): a new scoring system for scientific and clinical needs. Clin Oral Investig 2008;12(Suppl 1): S65-8.

10 British Society of Periodontology. Basic Periodontal Examination. 2011. http://www. bsperio.org.uk (accessed 14 Jun 2013).

11 Locker D, Quinonez C. To what extent do oral disorders compromise the quality of life? Comm Dent Oral Epidemiol 2011:39:3-11.

12 Vanhegan IS, Palmer-Green D, Soligard Tr, et al. The London 2012 Summer Olympic Games: an analysis of usage of the Olympic Village Polyclinic by competing athletes. Br J Sports Med 2013;47:415-19.

13 Bryant S, McLaughlin K, Morgaine K, et al. Elite athletes and oral health. Int J Sports Med 2011;32:720-4.

14 Callaghan MJ, Jarvis C. Evaluation of elite British cyclists: the role of the squad medical. Br J Sports Med 1996;30:349-53.

15 Gay-Escoda C, Vieira-Duarte-Pereira DM, Ardevol J, et al. Study of the effect of oral health on physical condition of professional soccer players of the Football Club Barcelona. Med Oral Patol Cir Bucal 2011;16:e436-9.

16 De Sant'Anna GR, Simionato MR, Suzuki ME. Sports dentistry: buccal and salivary profile of a female soccer team. Quint Int 2004;35:649-52.

17 Allen PF. Assessment of oral health related quality of life. Health Qual Life Outcomes 2003;1:40.

18 Foster Page LA, Thomson WM. Caries prevalence, severity, and 3-year increment, and their impact upon New Zealand adolescents' oral-health-related quality of life. J Publ Health Dent 2012;72:287-94.

19 Bastos RS, Carvalho S, Xavier A, et al. Dental caries related to quality of life in two Brazilian adolescent groups: a cross-sectional randomised study. Int Dent $J$ 2012:62:137-43.

20 Mulic A, Tveit A, Songe $D$, et al. Dental erosive wear and salivary flow rate in physically active young adults. BMC Oral Health 2012;12:8

21 Needleman I, McGrath C, Floyd P, et al. Impact of oral health on the life quality of periodontal patients. I Clin Periodontol 2004;31:454-7.

22 McNutt M, Partrick M, Shugars DA, et al. Impact of symptomatic pericoronitis on health-related quality of life. J Oral Maxillofac Surg 2008;66:2482-7.

23 Kerr L. Dental problems in athletes. Clin Sports Med 1983;2:115-22.

24 Coombes JS. Sports drinks and dental erosion. Am J Dent 2005;18:101-4.

25 Noble WH, Donovan TE, Geissberger M. Sports drinks and dental erosion. J Can Dent Assoc 2011;39:233-8.

26 Sirimaharaj V, Brearley Messer L, Morgan MV. Acidic diet and dental erosion among athletes. Aust Dent J 2002;47:228-36.

27 Gleeson M. Immune function in sport and exercise. J Appl Physiol 2007;103:693-9.

28 Rose G. Sick Individuals and sick populations. Int J Epidemiol 1985;14:32-8. 